\title{
Flip-Chip Bonding of MEMS Scanner for Laser Display Using Electroplated AuSn Solder Bump
}

\author{
Kun-Mo Chu, Student Member, IEEE, Won-Kyoung Choi, Young-Chul Ko, Jin-Ho Lee, \\ Hyo-Hoon Park, Member, IEEE, and Duk Young Jeon
}

\begin{abstract}
A MEMS scanner has been flip-chip bonded by using electroplated AuSn solder bumps. The microelectromechanical systems (MEMS) scanner is mainly composed of two structures having vertical comb fingers. To optimize the bonding condition, the MEMS scanner was flip-chip bonded with various bonding temperatures. Scanning electron microscopy (SEM) with an energy dispersive X-ray (EDX) spectroscopic system was used to observe the microstructures of the joints and analyze the element compositions of them. The die shear strength increased as the bonding temperature increased. During the thermal aging test, the delamination occurred at the interconnection of the MEMS scanner bonded at $340{ }^{\circ} \mathrm{C}$. It is inferred that the Au layer serving as pad metallization has been dissolved in the molten AuSn solder totally, and subsequently the $\mathrm{Cr}$ layer was directly exposed to the AuSn solder. Judging by the results of both die shear test and thermal aging test, the optimal bonding temperature was found to be approximately $320{ }^{\circ} \mathrm{C}$. Finally, using this MEMS scanner, we obtained an optical scanning angle of $32^{\circ}$ when driven by the ac control voltage of the resonant frequency in the range of 22.1-24.5 $\mathrm{kHz}$ with the $100-\mathrm{V}$ dc bias voltages.
\end{abstract}

Index Terms-AuSn solder, flip-chip bonding, microelectromechanical systems (MEMS), scanning mirror, thermal aging.

\section{INTRODUCTION}

W ITH THE advancement in display technologies, the needs for large area displays are increasing rapidly. Various kinds of projection displays have been available in the market, such as liquid crystal display (LCD), digital lightvalve projection (DLP), and liquid crystal on silicon (LCOS). Most projection displays currently use a lamp as a light source; however, there have been many efforts to establish the use of a laser as a light source due to its superior characteristics [1], [2]. The advantages of using a laser light for projection displays come from the original characteristics of a laser. The main advantages of scanning laser projection displays are high contrast ratio, excellent expression of natural color, and infinite depth of

Manuscript received August 16, 2005; revised May 30, 2006. This work was supported by the Center for Electronic Packaging Materials (ERC) of MOST/ KOSEF under Grant R11-2000-085-10001-0.

K.-M. Chu and D. Y. Jeon are with the Department of Materials Science and Engineering, Korea Advanced Institute of Science and Technology, Daejeon 305-701, Korea (e-mail: crysta@kaist.ac.kr).

W.-K. Choi is with the Packaging Center, Samsung Advanced Institute of Technology, Suwon 440-600, Korea.

Y.-C. Ko and J.-H. Lee are with the Materials and Device Laboratory, Samsung Advanced Institute of Technology, Suwon 440-600, Korea.

H.-H. Park is with the Optical Interconnection and Switching Laboratory, Information and Communications University, Daejeon 305-714, Korea.

Color versions of one or more of the figures in this paper are available online at http://ieeexplore.ieee.org.

Digital Object Identifier 10.1109/TADVP.2006.890209 focus [3]-[7]. To realize the laser display (laser TV) for home theater, it must have a compact size, low cost and low power consumption. Since module size is one of the important factors for cost reduction, the high-density integration should be done to make it compact [8]. In order to satisfy these requirements for the laser display, flip-chip bonding was applied to the assembly of the upper and lower combs of its microelectromechanical systems (MEMS) scanner.

Eutectic Au $80 \%-$ Sn $20 \%$ solder is commonly used for the flip-chip assembly in optoelectronic devices because fluxless soldering is possible [9]. Also, AuSn solder has been proven to provide interconnections with a high reliability due to its unique mechanical properties. However, a mechanical failure happens when the Kirkendall voids form between the Au layer and the $\mathrm{Au} / \mathrm{Sn}$ phases caused by the difference in the diffusion coefficients of $\mathrm{Au}$ and $\mathrm{Sn}$ by 15 orders of magnitude. Above all, the main difficulty in using this solder is to control exact composition of the 80Au20Sn eutectic composition. Because the liquidus lines are steep around the $\mathrm{Au}-\mathrm{Sn}$ eutectic composition, a little deviation from the eutectic composition results in a great increase of the liquidus temperature [10]-[12]. Therefore, optimization of bonding temperature and careful control of the solder composition are necessary to achieve a reliable interconnection using AuSn solder.

In this study, flip-chip bonding was performed with a precise alignment of $< \pm 1 \mu \mathrm{m}$. Also we optimized the flip-chip bonding temperature of the MEMS scanner having upper and lower combs using electroplated AuSn solder bumps.

\section{EXPERIMENTAL RESULTS}

\section{A. Structure and Fabrication}

Fig. 1 shows the schematic diagram of the MEMS scanner. We designed a new scanning mirror which has a circular mirror plate with an elliptical outer frame and is electrostatically driven by vertical combs arranged at the outer frame. This new scanning mirror looks like a human eye, so we named it an eye-type scanning mirror. This eye-type mirror showed a larger deflection angle compared to the rectangular and the elliptical mirrors [13]. It is composed of two structures having vertical combs. The upper structure is composed of vertical comb fingers (stationary electrodes), a supporting frame, gold signal lines, and pads on a trenched Pyrex glass substrate. The lower structure is composed of a scanning mirror plate, two torsion bars, a supporting frame, vertical comb fingers (moving electrodes and stationary electrodes), gold signal lines, and pads on a Pyrex glass substrate. The diameter of the scanning mirror plate is $1.0 \mathrm{~mm}$, 


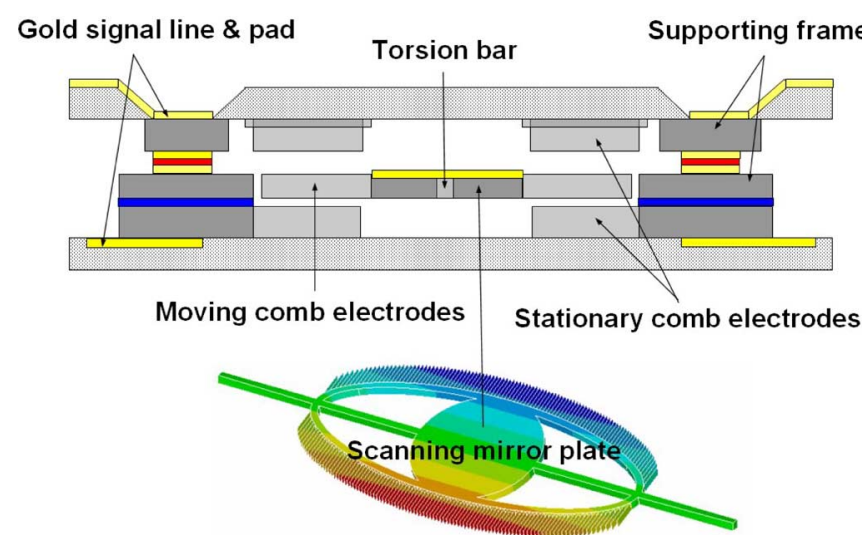

Fig. 1. Schematic image of the MEMS scanner with dual vertical comb structures.

\section{Lower structure}

(a)

(b)

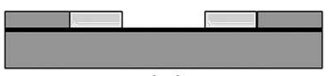

(c)

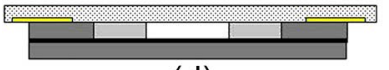

(d)

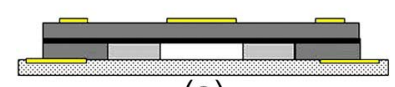

(e)

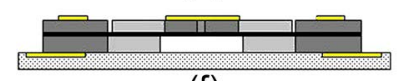

(f)
Upper structure

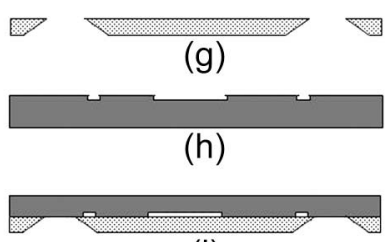

(i)

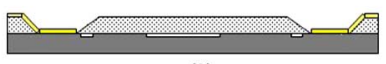

(j)

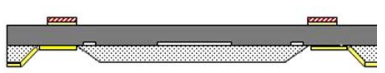

$(\mathrm{k})$

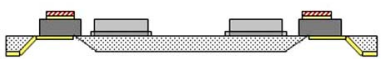

(l)

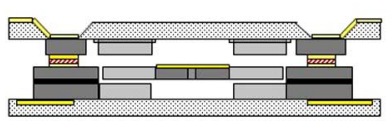

(m)

Pyrex glass $\square \mathrm{Cr} / \mathrm{Au}$
$\mathrm{SiO}_{2}$

AuSn

Fig. 2. Novel fabrication processes of the upper and lower structure. (a) Line groove etching. (b) $\mathrm{Cr} / \mathrm{Au}$ signal line formation. (c) Stationary comb etching. (d) Anodic bonding and polishing. (e) $\mathrm{Cr} / \mathrm{Au}$ layer formation. (f) Comb and torsion bar etching. (g) Through-hole formation. (h) Backside etching. (i) Anodic bonding and polishing. (j) $\mathrm{Cr} / \mathrm{Au}$ signal line formation. (k) AuSn electroplating. (1) Comb Etching. (m) Assembly (flip chip bonding).

and the upper and lower structures were assembled by flip-chip bonding with electroplated AuSn solder bumps.

Fig. 2 shows the fabrication processes of the upper and lower structure. The fabrication processes of the upper and lower structure were described in detail elsewhere [13]. In Fig. 2(b), the Pyrex glass substrate is turned upside down and $\mathrm{Cr} / \mathrm{Au}$ seed layer of $500 \AA / 3500 \AA$ is deposited. The AuSn electroplating was performed on top of $\mathrm{Cr} / \mathrm{Au}$ seed layer followed by thin $\mathrm{Au}$ plating to protect from surface oxidation. The weight percent ratio of $\mathrm{Au}: \mathrm{Sn}$ is 80:20 and the eutectic temperature of $\mathrm{AuSn}$ is $278^{\circ} \mathrm{C}$. To form a mold for AuSn electroplating on top of the supporting frame, a thick photoresist (AZ4620) is coated and patterned. The AuSn is electroplated using Sn buffered solution

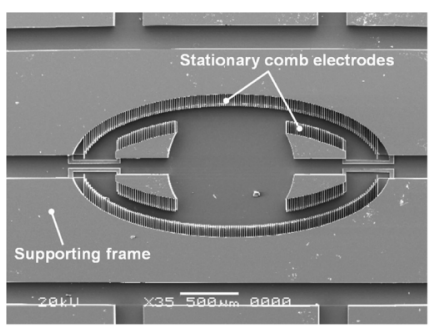

(a)

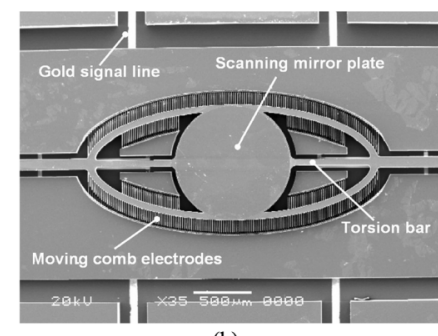

(b)
Fig. 3. SEM images of (a) upper structure and (b) lower structure.

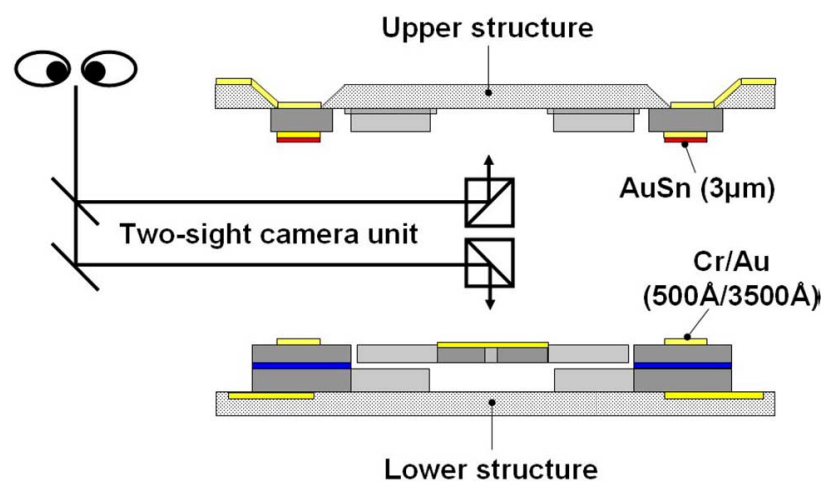

(a)

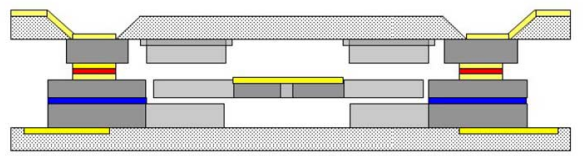

(b)

Fig. 4. Assembling processes of the scanning mirror. (a) Alignment and (b) flip-chip bonding.

with gold potassium cyanide $\left(\mathrm{KAu}(\mathrm{CN})_{2}\right)$. The electroplating bath is maintained at a temperature of $35^{\circ} \mathrm{C}$ and the current density of $6 \mathrm{~mA} \mathrm{~cm}^{-2}$ for $5 \mathrm{~min}$ to acquire the thickness of $3 \mu \mathrm{m}$. The eutectic AuSn solder can be prepared at both sides of the two structures. It can be electroplated at the upper structure in the process of Fig. 2(c) or at the lower structure between the process of Fig. 2(j) and (k). Fig. 3 shows the upper and lower structures of the scanning mirror.

\section{B. Flip-Chip Bonding}

To assemble the upper and lower structures having vertical comb fingers, flip-chip bonding was used. Fig. 4 shows the assembling processes of the scanning mirror. Unit devices of the upper and lower structures are aligned by the alignment marks and bonded using a flip-chip bonder (Toray, FC 1500 series). In this system, as shown in Fig. 4, the upper structure is picked up by vacuum to a bonding head and the lower structure is also fixed by vacuum onto the bonding stage. For the upper and lower structure alignment, a two-sight camera unit is inserted between the upper and lower structure and read positions of the upper and lower structure, and then positional shift will be adjusted with the stage. After the camera unit retracts, the bonding head is lowered, and subsequently heating, pressurization, bonding, and cooling processes follow [14]. During the soldering process, the bonding alignment was improved by the sur- 


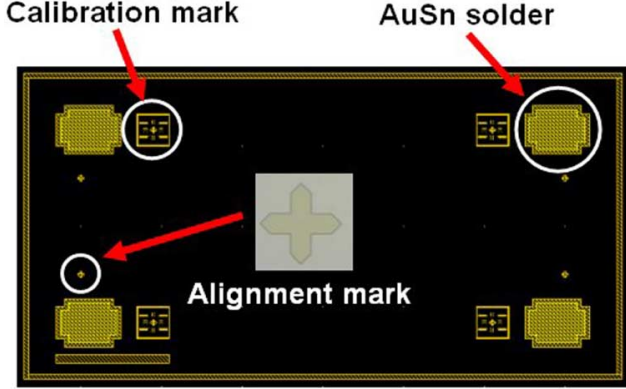

(a)

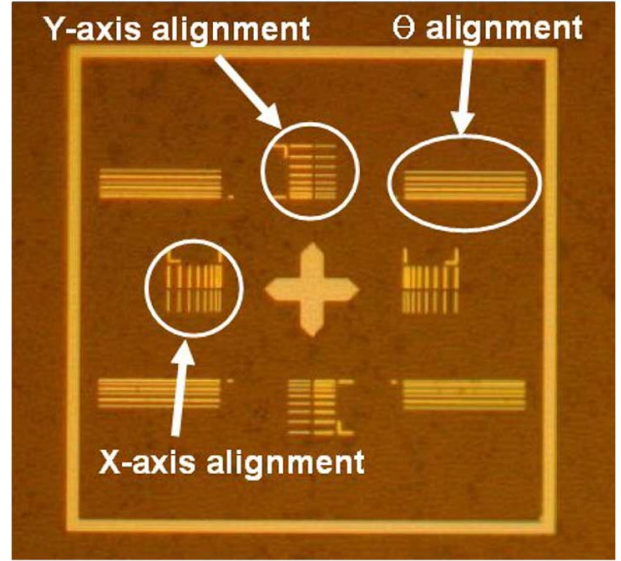

(b)

Fig. 5. Images of (a) reference glass chip including AuSn solder bumps and (b) calibration mark.

face tension of solder. In this study, the upper and lower structures were flip-chip bonded with various bonding temperatures during $20 \mathrm{~s}$. The bonding temperatures were $300{ }^{\circ} \mathrm{C}, 320^{\circ} \mathrm{C}$, $340{ }^{\circ} \mathrm{C}$, and the bonding pressures were $120 \mathrm{gf}$.

To achieve high alignment accuracy, a glass reference chip having the same size with the real structure was used for calibration of alignment. Since the glass reference chip is transparent, we could directly adjust the positional shift in the software after test flip-chip bonding. Fig. 5(a) shows the CAD image of the reference glass chip including AuSn solder bumps located at each corner. When the reference glass chip having several calibration marks [Fig. 5(b)] was bonded, the information of both positional ( $X$ and $Y$ axis) and orientation $(\theta)$ shifts could be obtained using image processing monitor. Using this reference glass chip, we could successfully perform a flip-chip bonding with precise alignment of $< \pm 1 \mu \mathrm{m}$. In this study, flip-chip bonding was performed with a precise alignment of $< \pm 1 \mu \mathrm{m}$. Also we optimized the flip-chip bonding temperature of the MEMS scanner having upper and lower combs using electroplated AuSn solder bumps.

\section{RESULTS AND DISCUSSION}

\section{A. Surface Observations of AuSn Solder Bump After Reflow Process}

Ivey [10] reported that a deviation of $1 \mathrm{wt} \% \mathrm{Au}$ from the eutectic composition towards the Au-rich side would result in an approximately $30^{\circ} \mathrm{C}$ increase in the liquidus temperature. Thus, careful process control of both the solder composition

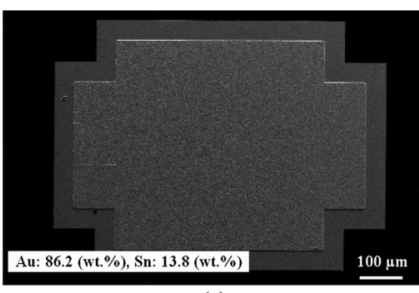

(a)

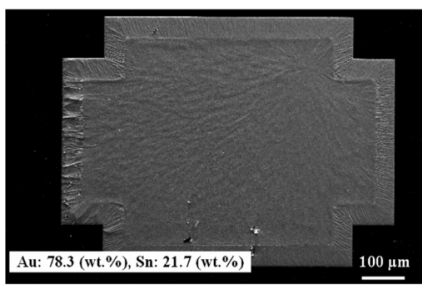

(c)

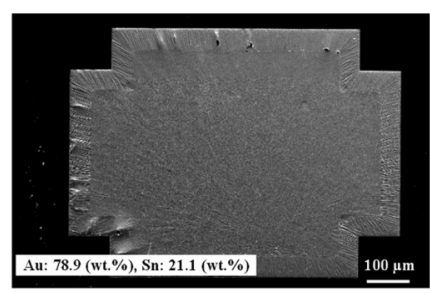

(b)

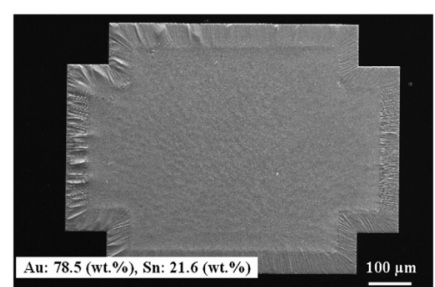

(d)
Fig. 6. SEM images of AuSn solder bumps with the composition after reflow process. (a) As deposited and reflowed at (b) $300^{\circ} \mathrm{C}$, (c) $320^{\circ} \mathrm{C}$, and (d) $340^{\circ} \mathrm{C}$.

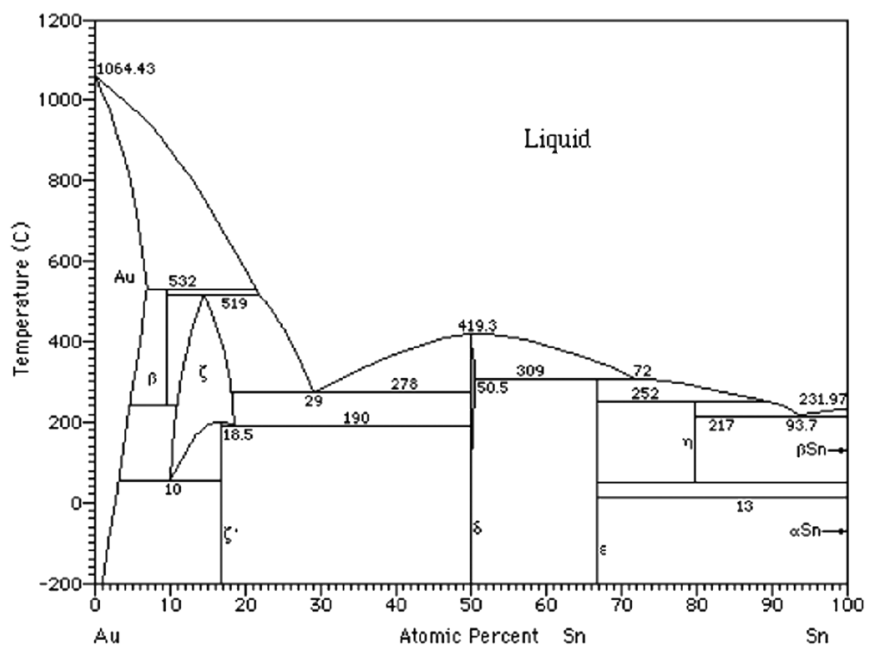

Fig. 7. Phase diagram between Au and Sn.

and the bonding temperature is necessary for the successful strong bonding. Scanning electron microscopy (SEM) and energy dispersive X-ray (EDX) analyses are used to examine the morphology and element compositions of each bump surface according to reflow temperatures as shown in Fig. 6. The composition of the deposited AuSn solder bump after reflow was near to the eutectic composition (80 wt.\% Au-20 wt.\% Sn) regardless of the reflow temperature $\left(>280^{\circ} \mathrm{C}\right)$.

\section{B. Analysis of Interface Between AuSn Solder Bump and Chip Pad After Flip-Chip Bonding}

In the Au-Sn binary phase diagram shown in Fig. 7, the AuSn system has a complex equilibrium phase diagram. It is known that at a relative low temperature, such as the room temperature, rapid diffusion of $\mathrm{Au}$ and $\mathrm{Sn}$ can occur in the $\mathrm{Au} / \mathrm{Sn}$ thin layer system. Even in as-evaporated AuSn thin films, it was found that three phases, AuSn, $\mathrm{AuSn}_{2}$, and $\mathrm{AuSn}_{4}$, were formed due to interdiffusion of $\mathrm{Au}$ and $\mathrm{Sn}$ [15]. The cross sections of interfaces were investigated by analyzing the microstructure and composition of a joint using SEM and EDX. Fig. 8 exhibits SEM images of interfaces between AuSn solder bump and the chip (=upper 


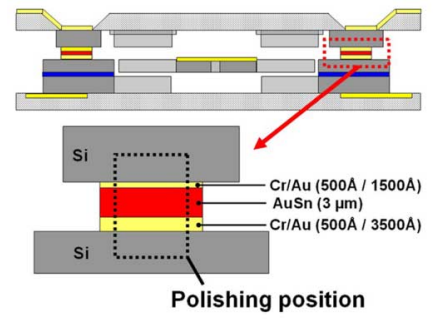

(a)

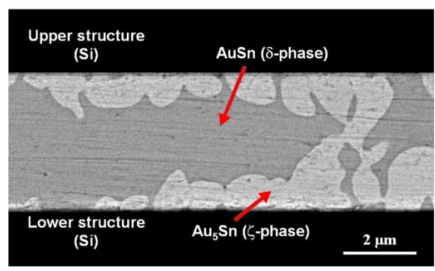

(c)

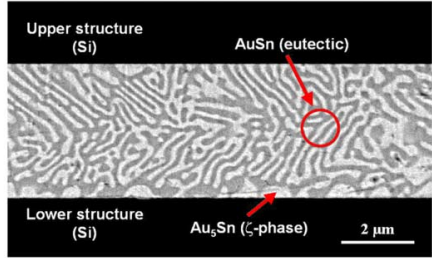

(b)

(d)

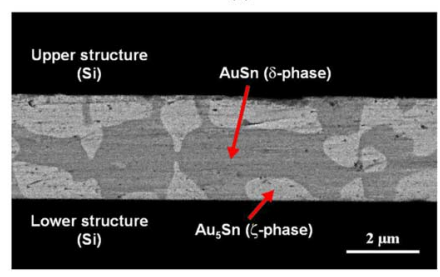

Fig. 8. Cross-sectional SEM images of joints bonded at (a) $300^{\circ} \mathrm{C}$, (b) $320^{\circ} \mathrm{C}$, and (c) $340{ }^{\circ} \mathrm{C}$.

structure) pad at each bonding temperature. SEM and EDX results indicate that the joint consists of Au-Sn alloy which is composed of two phases (gray: $\delta-\mathrm{AuSn} / \mathrm{bright:} \mathrm{Au}_{5} \mathrm{Sn}$ ). The grains of both the upper and lower intermetallic compounds (IMCs) were revealed as $\mathrm{Au}_{5} \mathrm{Sn}$ ( $\zeta$-phase) by the EDX analysis. The upper $\zeta$-phase formed between the chip pad $(\mathrm{Cr} / \mathrm{Au})$ and the AuSn solder bump grew from top to bottom. Also the lower $\zeta$-phase formed between the AuSn solder bump and the chip pad $(\mathrm{Cr} / \mathrm{Au})$ of the substrate (=lower structure) grows from bottom to top. Above the $320^{\circ} \mathrm{C}$ up to $519^{\circ} \mathrm{C}$, the $\zeta$-phase was still stable. Elger et al. [16] reported that the IMCs prevent the bump from interacting with the chip pad because it has a high decomposing temperature $\left(519^{\circ} \mathrm{C}\right)$. Also, $\zeta$-phase does not decompose at the reflow temperature of Au80Sn20 any more because the $\zeta$-phase is stable up to $519^{\circ} \mathrm{C}$.

\section{Die Shear Test}

The die shear test was conducted to investigate the change of die shear strength for various bonding temperatures. The lower structure was clamped and shear force was applied at the edge of the upper structure. The traveling speed of the stylus positioned at $5 \mu \mathrm{m}$ above from the surface of the lower structure was $100 \mu \mathrm{m} / \mathrm{s}$. Fig. 9 shows the measured die shear strength for various bonding temperatures after flip-chip assembly. The die shear strength increased as the bonding temperature increased. While the intermetallic compound (IMC) forms at the interface between solder and substrate during the soldering process. There are some reports on the correlation between growth of IMC and shear strength. They reported that the initial formation of the IMC at the interface means a good metallurgical bonding [17]-[19]. However, an overgrown IMC is known to be detrimental to the joint strength due to the brittle nature of IMCs. This implies that there exists a critical thickness of the IMC layer at which the mechanical properties of solder joint are optimized [20], [21]. As shown in Fig. 9, die shear strength was almost saturated at temperature range between $320^{\circ} \mathrm{C}$ and $340^{\circ} \mathrm{C}$. This means that there exists a critical thickness of IMC

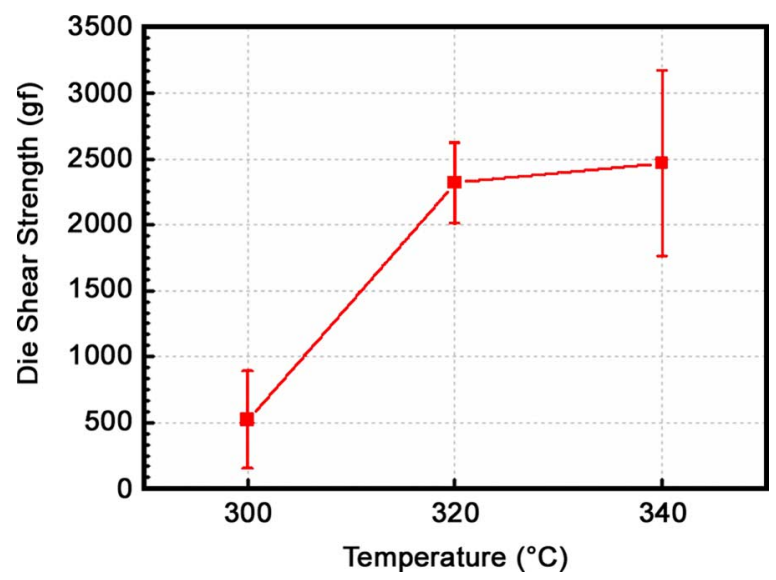

Fig. 9. Result of the die shear strength of flip-chip bonded module.
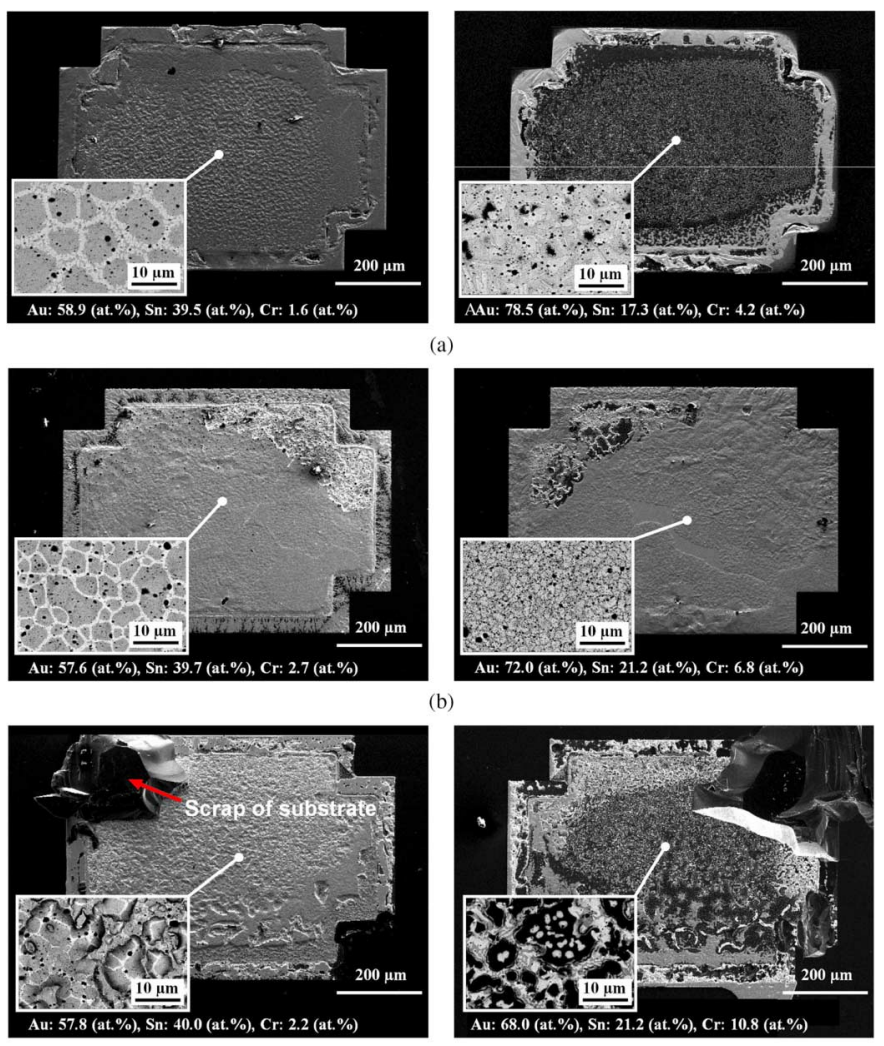

Fig. 10. Fractured surfaces of chips and substrates bonded at (a) $300{ }^{\circ} \mathrm{C}$, (b) $320{ }^{\circ} \mathrm{C}$, and (c) $340{ }^{\circ} \mathrm{C}$ after die shear test. (Left side image: chip, right side image: substrate)

layer at which the die shear strength is maximized. SEM and EDX analyses were performed on each fractured surfaces of the chip and substrate pads.

Fig. 10 shows the fractured surfaces of the chip and substrate pads after the die shear test. Fractures occurred mostly between the AuSn solder bumps formed at chip and the substrate pads during the die shear test. There are AuSn solder and the IMC has spalled away around the edge area of chip. While a little IMC can be observed mainly at the inner area of chip, as shown in Figs. 10(a) and (b). In Fig. 10(c), the scrap of substrate is found on the fractured surface of chip. From the EDX analysis, 


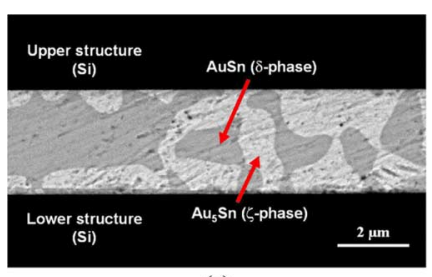

(a)

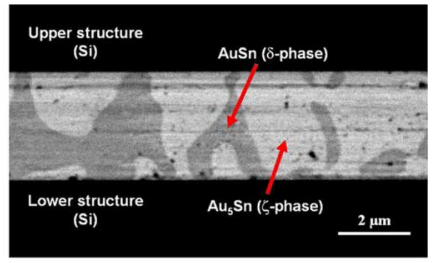

(b)

Fig. 11. Cross-sectional SEM images of joints bonded at (a) $300{ }^{\circ} \mathrm{C}$ and (b) $320^{\circ} \mathrm{C}$ after thermal aging at $120^{\circ} \mathrm{C}$ for $100 \mathrm{~h}$.

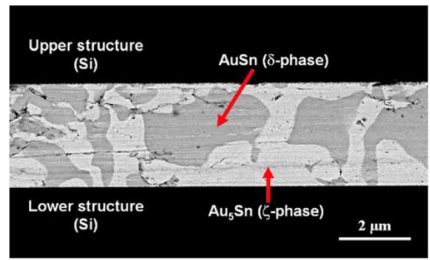

(a)

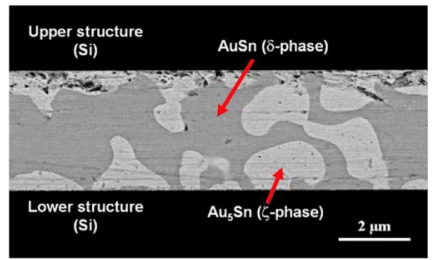

(b)
Fig. 12. Cross-sectional SEM images of joints bonded at (a) $300{ }^{\circ} \mathrm{C}$ and (b) $320^{\circ} \mathrm{C}$ after thermal aging at $120^{\circ} \mathrm{C}$ for $400 \mathrm{~h}$.

Cr was detected as 10.8 at.\% at the fractured surface of substrate assembled at $340^{\circ} \mathrm{C}$. It seems that $\mathrm{Au}$ was dissolved into the molten AuSn solder and consumed out. As a result, the $\mathrm{Cr}$ was revealed to molten solder and resulted in the weak bonding. Consequently, the fracture occurred at the interface between $\mathrm{Cr}$ and $\mathrm{Au}_{5} \mathrm{Sn}$.

\section{Effects of Aging on the AuSn Solder Bump Interconnection}

The flip-chip assembled samples were aged at $120^{\circ} \mathrm{C}$ for 100 and $400 \mathrm{~h}$, respectively. The corresponding cross sections are given in Figs. 11 and 12. When the thermal aging test was finished, the chip and substrate bonded at $340{ }^{\circ} \mathrm{C}$ were fallen apart. The microstructures of the joint were almost the same regardless of the aging time. While the amount of $\zeta$-phase increased at $320{ }^{\circ} \mathrm{C}$, compared to the joint that was bonded at $300{ }^{\circ} \mathrm{C}$. After aging for 100 and $400 \mathrm{~h}$, it seems that $\mathrm{Au}_{5} \mathrm{Sn}$ phase forms more in the sample bonded at $320{ }^{\circ} \mathrm{C}$ than in the one bonded at $300{ }^{\circ} \mathrm{C}$. It indicates that the diffusion of $\mathrm{Au}$ from the pad was more attributed to the formation of $\mathrm{Au}_{5} \mathrm{Sn}$ phase in the solder joint.

Fig. 13 shows the cross-sectional SEM image of a failed solder joint boned at $340{ }^{\circ} \mathrm{C}$ after $100 \mathrm{~h}$ aging. It seems that the separation occurred at the interface between $\mathrm{Cr}$ and $\mathrm{Au}_{5} \mathrm{Sn}$ solder during the aging. Even though the first failure was observed after 100-h aging test, the first time to failure would have occurred earlier. It is inferred that the Au layer (3500- $\AA$ thick) serving as pad metallization has been totally dissolved into the molten AuSn solder. Then Cr layer directly contacted to the AuSn solder that did not wet with $\mathrm{Cr}$. As a result, the delamination occurs between $\mathrm{Cr}$ layer and $\mathrm{Au}_{5} \mathrm{Sn}$ solder. A similar result was reported by Liu et al. using the eutectic $\mathrm{SnPb}$ solder and $\mathrm{Au} / \mathrm{Cr} / \mathrm{Cu} \mathrm{UBM}$ system. They observed in the molten state, the solder would dewet from the $\mathrm{Cr}$ surface after the $\mathrm{Cu}-\mathrm{Sn}$ compound has spalled away [22]-[24]. Therefore, the adhesion between $\mathrm{Cr}$ and the solder in the solid state must be poor. As mentioned above in Section III-C, although the

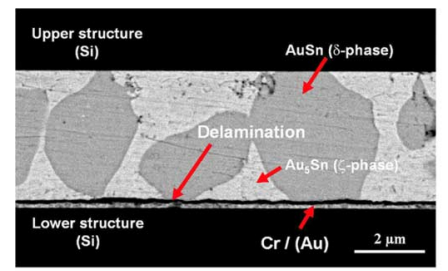

(a)

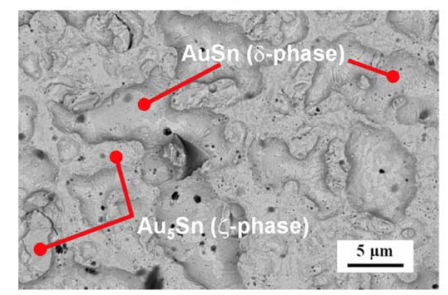

(c)

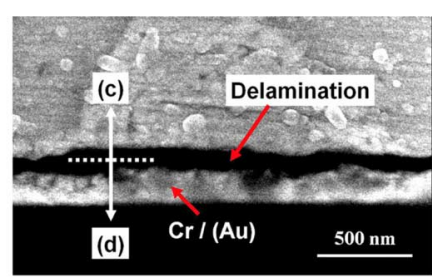

(b)

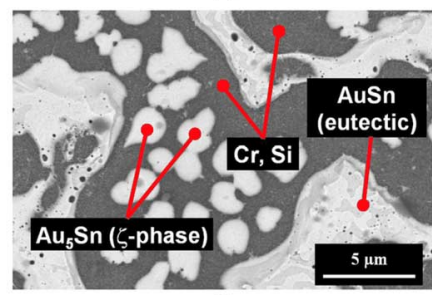

(d)
Fig. 13. SEM image of (a) failed solder joint (cross section) boned at $340{ }^{\circ} \mathrm{C}$ (b) Local view of delamination (magnification: $50000 \mathrm{X}$ ), fractured surface of (c) chip and (d) substrate after 100-h aging test.

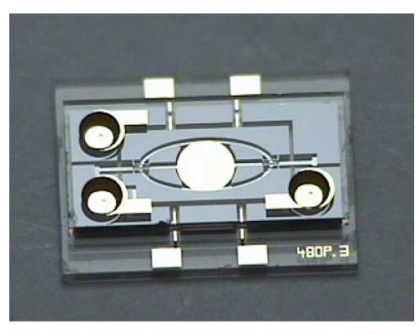

(a)

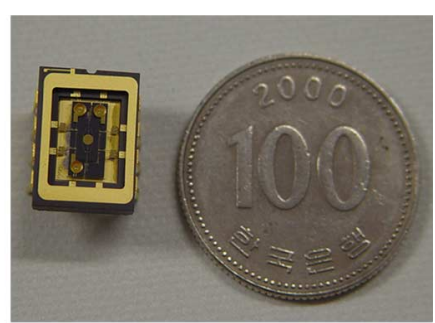

(b)
Fig. 14. Image of (a) flip-chip assembled eye-type scanning mirror and (b) prototype of packaged scanning mirror.

shear strength is the highest when the bonding temperature was $340{ }^{\circ} \mathrm{C}$, the crack could occur during the thermal aging condition. Considering both mechanical and thermal reliabilities, the appropriate bonding temperature was determined to be $320^{\circ} \mathrm{C}$.

\section{E. Performance of Flip-Chip-Assembled MEMS Scanner}

Fig. 14 shows the upper and lower structures of the scanning mirror prototype. Fig. 15 depicts the resonant frequency of the scanning mirror as a function of spring length. The resonant frequency was measured in the range of $22.1-24.5 \mathrm{kHz}$ depending on the spring length. Fig. 16 shows the deflection angle variation of the scanning mirror with an increase in the applied voltage. The dc bias voltages were applied to the stationary comb electrodes of the upper and lower structures, and the sinusoidal control voltage of a resonant frequency was applied to the moving comb electrodes of the lower structure. As the driving voltage was raised, the scanning angle was also increased linearly. The characteristic of linear control can be explained by the linear control scheme [25].

Using this scanning mirror, we successfully acquired the optical scanning angle of $32^{\circ}$ when driven by the $65-75-\mathrm{V}$ sinusoidal control voltage of the resonant frequency in the range of $22.1-24.5 \mathrm{kHz}$ with the $100-\mathrm{V}$ dc bias voltages. As a result, we could increase the performance of the scanning mirror such as a high driving frequency and a large scanning angle by reducing the moment of inertia and increasing the rotation moment [13]. 


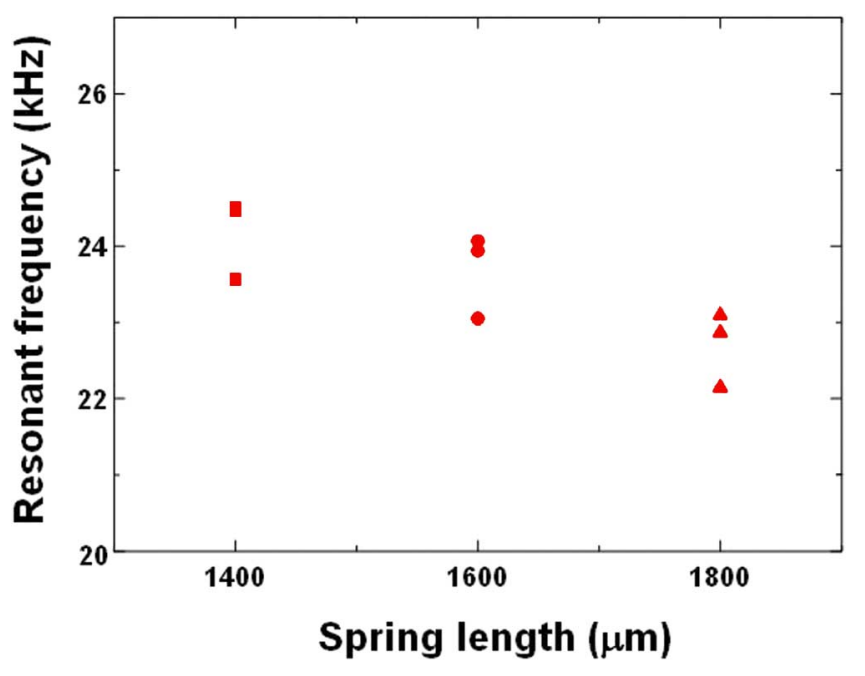

Fig. 15. Resonant frequency according to the three kinds of spring.

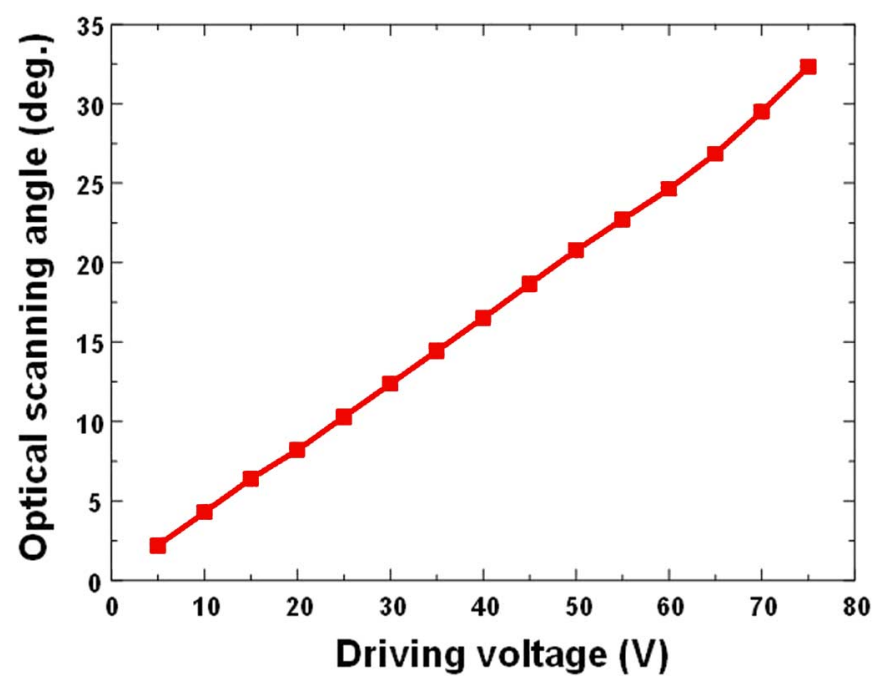

Fig. 16. Deflection angle of the scanning mirror.

\section{CONCLUSION}

Flip-chip bonding was used for assembling a MEMS scanner having vertical comb fingers with the electroplated AuSn solder. When the AuSn solder was reflowed at different temperatures, the surface roughness of solder bump was changed but kept the eutectic composition regardless of reflow temperature. The die shear strength increased as the bonding temperature increased. SEM and EDX results indicate that the joint consists of AuSn and intermetallic compound [IMC, $\mathrm{Au}_{5} \mathrm{Sn}(\zeta$-phase)] grains. During the aging test, the delamination occurred between the AuSn solder bump and the pad (Cr layer) in the case of bonding temperature of $340^{\circ} \mathrm{C}$. It is inferred that Au layer is consumed and then AuSn solder directly contacts to the Cr layer. On the basis of both the die shear test and thermal aging test, the appropriate bonding temperature was found to be approximately $320^{\circ} \mathrm{C}$ in this study. Using this scanning mirror, we successfully acquired the optical scanning angle of $32^{\circ}$ when driven by the $65-75-\mathrm{V}$ sinusoidal control voltage of the resonant frequency in the range of $22.1-24.5 \mathrm{kHz}$ with the $100-\mathrm{V}$ dc bias voltages. Finally, the flip-chip assembled MEMS scanner showed a very linear actuating performance and could be used for full color laser scanning display with XGA-resolution.

\section{ACKNOWLEDGMENT}

The authors would like thank Dr. J.-W. Cho for his assistance in the module design and $\mathrm{H}$. K. Jeong for device fabrication preparations.

\section{REFERENCES}

[1] E. Takeuchi, G. Flint, R. Bergstedt, P. Solone, D. Lee, and P. Moulton, "Laser digital cinema," Proc. SPIE, vol. 4294, pp. 28-35, 2001.

[2] K. W. Kennedy, R. J. Martinsen, A. J. Radl, J. F. Arntsen, and M. Karakawa, "Laser-based SXGA reflective light valve projector with E-cinema quality contrast and color space," Proc. SPIE, vol. 3954, pp. 168-174, 2000.

[3] G. Hollemann, B. Braun, F. Dorsch, P. Hennig, P. Heist, U. Krause, U. Kutschki, and H. Voelckel, "RGB lasers for laser projection displays," Proc. SPIE, vol. 3954, pp. 140-151, 2000.

[4] A. Nobel, B. Ruffing, and R. Wallenstein, "Diode pumping sharpens large laser displays," Laser Focus World, pp. 263-266, 1999.

[5] Y. M. Hwang, J. H. Lee, Y. J. Park, S. N. Cha, and Y. H. Kim, "200-in. full-color laser projection displays," Proc. SPIE, vol. 3296, pp. 116-125, 1998.

[6] J. Lee, Y. Hwang, J. Park, Y. Park, Y. Kim, H. Lee, S. Cha, S. Hong, and H. Jang, "Large-area laser projection system using a white laser," in SID Int. Symp. Tech. Dig., 1997, vol. 28, pp. 631-634.

[7] Y. H. Kim, H. W. Lee, S. N. Cha, J. H. Lee, Y. J. Park, J. H. Park, S. S. Hong, and Y. M. Hwang, "Full color laser projection display using $\mathrm{Kr}$-Ar laser (white laser) beam-scanning technology," Proc. SPIE, vol. 3131, pp. 2-10, 1997.

[8] J.-H. Lee, Y.-C. Ko, B.-S. Choi, J.-M. Kim, and D. Y. Jeon, "Characterization of silicon scanning mirror for laser display," Jpn. J. Appl. Phys., vol. 41, pp. 5853-5857, 2002.

[9] M. Hutter, H. Oppermann, G. Engelmann, J. Wolf, O. Ehrmann, R. Aschenbrenner, and H. Reichl, "Calculation of shape and experimental creation of AuSn solder bumps for flip chip applications," in Proc. Electron. Compon. Technol. Conf., 2002, pp. 282-288.

[10] D. G. Ivey, "Microstructural characterization of Au/Sn solder for packaging in optoelectronic applications," Micron, vol. 29, no. 4, pp. 281-287, 1998.

[11] E. Zakel, J. Gwiasda, J. Kloeser, J. Eldring, G. Engelmann, and H. Reichl, "Fluxless flip chip assembly on rigid and flexible polymer substrates using the Au-Sn metallurgy," in Proc. 1994 IEMT Symp., 1994, pp. $177-184$.

[12] J. Sasaki, M. Itoh, T. Tamanuki, H. Hatakeyama, S. Kitamura, T. Shimoda, and T. Kato, "Multiple-chip precise self-aligned assembly for hybrid integrated optical modules using Au-Sn solder bumps," IEEE Trans. Adv. Packag., vol. 24, no. 2, pp. 569-575, May 2001.

[13] Y.-C. Ko, J.-W. Cho, Y.-K. Mun, H.-G. Jeong, W.-K. Choi, J.-H. Lee, J.-W. Kim, J.-B. Yoo, and J.-H. Lee, "Eye-type scanning mirror with dual vertical combs for laser display," Proc. SPIE, vol. 5721, pp. 14-22, 2005.

[14] A. Yamauchi and Y. Arai, "Analysis and measures against heat-expansion for sub-micron LD assembly by passive alignment," in Proc. Electron. Compon. Technol. Conf., 2001, pp. 242-246.

[15] W. Pittroff, T. Reiche, J. Barnikow, A. Klein, K. Vogel, and J. Wurfl, "Au-Sn solder bumps with tungsten silicide based barrier metallization schemes," Appl. Phys. Lett., vol. 67, no. 16, pp. 2367-2369, 1995.

[16] G. Elger, J. Voigt, and H. Oppermann, "Application of flip-chip-bonders in AuSn solder processes to achieve high after bonding accuracy for optoelectronic modules," in Proc. Lasers and Electro-Optics Soc., 2001, vol. 2, pp. 437-438.

[17] J. H. Lau, Solder Joint Reliability. New York: Van Nostrand Reinhold, 1991, pp. 406-454.

[18] P. L. Tu et al., "Effect of intermetallic compounds on the thermal fatigue of surface mount solder joints," IEEE Adv. Packag., vol. 20, pp. 87-93, 1997.

[19] S. W. Yoon et al., "Effect of under bump metallurgy and reflows on shear strength and microstructure of joint between $\mathrm{Cu}$ substrate and Sn-36Pb-2Ag solder alloy," Mater. Trans., vol. 44, no. 2, pp. 290-297, 2003.

[20] S. F. Drinfleid and J. J. Ramon, "Microstructure investigation of $\mathrm{Cu}-\mathrm{Sn}$ intermetallics and the influence of layer thickness on the shear strength," Welding J., pp. 373s-377s, 1990. 
[21] C.-K. Shin and J.-Y. Huh, "Effect of Cu-containing solders on the critical IMC thickness for the shear strength of BGA solder joints," in Proc. Electron. Packag. Technol. Conf., 2000, pp. 406-411.

[22] C. Y. Liu, C. Chen, A. K. Mal, and K. N. Tua, "Direct correlation between mechanical failure and metallurgical reaction in flip chip solder joints," J. Appl. Phys., vol. 85, no. 7, pp. 3882-3886, 1999.

[23] C. Y. Liu, H. K. Kim, K. N. Tu, and P. A. Totta, "Dewetting of molten $\mathrm{Sn}$ on $\mathrm{Au} / \mathrm{Cu} / \mathrm{Cr}$ thin-film metallization," Appl. Phys. Lett., vol. 69, no. 26, pp. 4014-4016, 1996.

[24] D. W. Zheng, Z. Y. Jia, C. Y. Liu, W. J. Wen, and K. N. Tu, "Size dependent dewetting and sideband reaction of eutectic $\mathrm{SnPb}$ on $\mathrm{Au} / \mathrm{Cu} / \mathrm{Cr}$ multilayered thin film," J. Mater. Res., vol. 13, no. 5, pp. 1103-1106, 1998.

[25] L.-S. Fan, H. H. Ottensen, T. C. Reiley, and R. W. Wood, "Magnetic recording head positioning at very high track densities using a microactuator-based, two-stage servo system," IEEE Trans. Ind. Electron., vol. 42, no. 7, pp. 3882-3886, Jul. 1999.

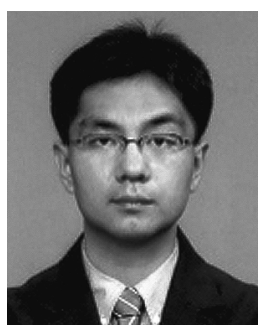

Kun-Mo Chu (S'06) received the B.S. degree in materials science and engineering from Korea University, Seoul, Korea, in 2001 and the M.S. degree in materials science and engineering from the Korea Advanced Institute of Science and Technology (KAIST), Daejeon, Korea, in 2003. He is currently pursuing the Ph.D. degree at KAIST.

His research interests include optical interconnection architecture and flip-chip technology for electronic and photonic devices.

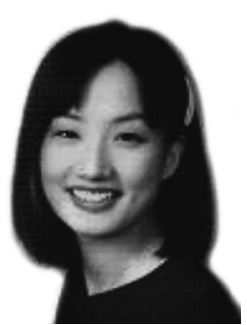

Won-Kyoung Choi received the B.S., M.S., and $\mathrm{Ph} . \mathrm{D}$. degrees in materials science and engineering from the Korea Advanced Institute of Science and Technology (KAIST), Daejeon, Korea, in 1995, 1997, and 2001, respectively.

From 2001 to 2002, she was with the IBM T. J. Watson Research Center on a Postdoctoral Fellowship. Since 2003, she has been with the Packaging Center, Samsung Advanced Institute of Technology, Suwon, Korea, as a Member of Research Staff in the Micro Device and System Laboratory.

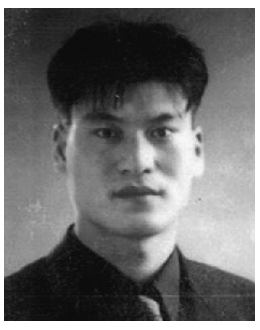

Young-Chul Ko received the B.S. and M.S. degrees in physics from Myungji University, Yongin, Korea, in 1998 and 2000, respectively. He is currently pursuing the Ph.D. degree in an interdisciplinary program in the nanoscience of technology at Sungkyunkwan University, Suwon, Korea.

Since 2000, he has been with Samsung Advanced Institute of Technology, Suwon, Korea, as a Member of Research Staff in the Materials and Device Laboratory. His research interests include design and fabrication of optical MEMS scanners, nanofabrication processes, and optical packaging.

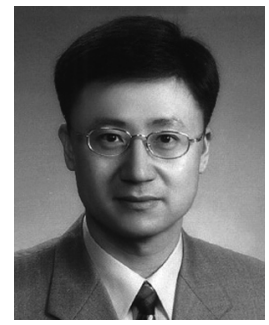

Jin-Ho Lee received the B.S. degree in metallurgical engineering from Hanyang University, Seoul, Korea, in 1989, the M.S. degree in materials science and engineering from Pohang University of Science and Technology, Pohang, Korea, in 1991, and the $\mathrm{Ph} . \mathrm{D}$. degree in Materials Science and Engineering from Korea Advanced Institute of Science and Technology, Daejon, Korea, in 2003.

Since 1992, he has been with the Samsung Advanced Institute of Technology, Suwon, Korea, as a Member of Research Staff for SHG green laser and Laser TV development in the Micro Systems Laboratory. Since 2000, he has served as a Project Manager of laser display development. His research interests include laser display optics, modulators, and optical MEMS scanners.

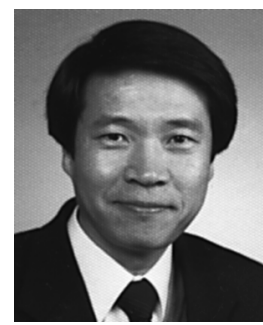

Hyo-Hoon Park (M'94) received the Ph.D. degree in material science and engineering from the Korea Advanced Institute of Science and Technology (KAIST), Daejeon, in 1985.

From 1985 to 1986, he worked in the area of compound semiconductor devices at Stanford University, Stanford, CA, as a Postdoctoral Scholar. From 1986 to 1997, he worked at the Electronics and Telecommunications Research Institute in the area of highspeed electronic devices and vertical-cavity surfaceemitting lasers. Since 1998, he has been a Professor in the Optical Communication Group, Information and Communications University (ICU), Daejeon. Since joining ICU, he has been studying optical interconnections for chip-to-chip and board-to-board data link, optical transceiver modules, and optical switching components for optical communication systems and networks.

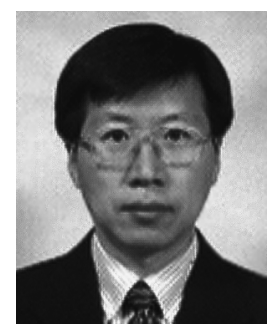

Duk Young Jeon received the B.S. degree from Seoul National University, Seoul, Korea, in 1976, the M.S. degree in applied physics from the Korea Advanced Institute of Science and Technology (KAIST), Daejeon, in 1979, and the Ph.D. degree in physics from Lehigh University, Bethlehem, PA, in 1988.

In 1988, he joined AT\&T Bell Laboratories, Allentown, PA, as Member of Technical Staff, where he was involved in the development of advanced lithography for submicron CMOS technology. Later, he was involved in researching gate technology for $0.1-\mu \mathrm{m}$ CMOS and plasma processing and device study for the high-speed BiCMOS technology at AT\&T in Holmdel, NJ, and back-end integration for deep submicron modular BiCMOS technology at AT\&T in Murray Hill, NJ. Since 1994, he has been with KAIST as a Professor of materials science and engineering. His research interests are in display materials and devices, such as phosphors, carbon nanotubes, electron multiplier channel plates, optical packaging, and optical MEMs devices. 